
\title{
$\begin{array}{ll}\text { Research Square } & \text { They should not be considered conclusive, used to inform clinical practice, } \\ \text { or referenced by the media as validated information. }\end{array}$
}

\section{Infanticide, Neonaticide and Post-neonaticide: Racial/ethnic Disparities in the United States.}

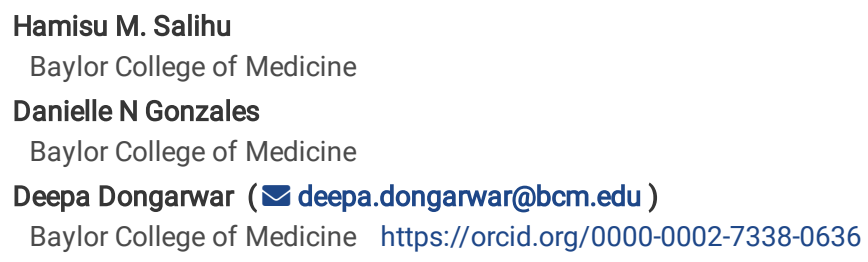

\section{Research Article}

Keywords: Infanticide, Neonaticide, Post-Neonaticide, Homicide, Infants, Neonates

Posted Date: March 13th, 2021

DOI: https://doi.org/10.21203/rs.3.rs-297298/v1

License: () (i) This work is licensed under a Creative Commons Attribution 4.0 International License. Read Full License 


\section{Abstract}

This study aims to assess recent trends and characteristics for infanticide and the sub-groups: neonaticide and post-neonaticide during the time period 20032017. Multiple Cause-of-Death Mortality Data were used to identify infanticides in the United States based on ICD-10 codes. Joinpoint regression analysis was used to calculate trends in the rates of infanticide, neonaticide and post-neonaticide during the study period. Logistic regression was used to examine the association between the socio-demographic characteristics and each of the outcomes. During the study period, 4,545 (1.2\%) infants were identified as being victims of infanticide. The rates of neonaticide declined by $4.2 \%$ over the study period, whereas that of infanticide and post-neonaticide remained statistically unchanged. Males and Non-Hispanic (NH) Blacks were more likely to be victims of infanticide and post-neonaticide, compared to females and NH-Whites respectively, but had similar likelihood of neonaticide. While foreign-born residents exhibited nearly a four-fold increased likelihood of neonaticide, they had about 70\% lesser likelihood of post-neonaticide than US born residents. Conclusion: Reasons for the disparities found in this study are multifactorial. We believe that access to healthcare needs to be improved and community resources need to be made more available to address the proposed mechanisms that lead to infanticide.

\section{Introduction}

Infanticide is a sub-group of infant mortality, in which an infant less than 1 year of age is a victim of homicide. Neonaticide is a sub-category of infanticide and although it has several different definitions in the literature, this paper will refer to neonaticide as being a homicide against a child that is 1 month of age or less. Post-neonaticide is another sub-category of infanticide, which is defined as homicide against a child that is over 1 month of age but less than 1 year of age.

Several factors contribute to infant mortality each year, and the most frequent are congenital anomalies, prematurity, cardiovascular/respiratory/infectious causes and injury [1]. Injury can be sub-divided into unintentional and intentional. Among injury-related causes of death in infants less than 1 year of age, homicide has consistently been ranked as the 2 nd leading cause of injury-related death in this age group [1].

A number of studies have analyzed various aspects of infant homicide, aspects of the act of homicide, perpetrator characteristics and victim characteristics. About $50 \%$ of infant homicides (less than 1 year of age) occur by the 4 th month of life and $67 \%$ occur by the 6 th month of life [2]. Fujiwara et al. assessed homicides of children less than 2 years of age from 2001-2005 and categorized the causes of death as type 1 (beating/shaking injuries) and type 2 (all other homicides, including neonaticide). The study found that $75 \%$ of fatal injuries were type 1 injuries, the remainder being type 2 [3]. Some studies have reported the common methods of homicide against newborns to be asphyxiation and drowning [4]. However, other studies have found it difficult to classify causes of death based on death certificate documentation [2].

Regarding perpetrators, mothers are more likely to commit homicide in the first week of life, but after the first week of life, the perpetrator is equally likely to be a male or a female [5]. Fuijwara et al, found that males were more likely to commit type 1 injuries (beating/shaking injuries, shooting), while women were more likely to commit type 2 injuries (drowning, poisoning, suffocation, strangulation, etc.) $[3,6]$. Some investigators have also determined perpetrators are more likely to be young, unmarried, maternal lack of prenatal care, non-hospital birth, fewer years of formal education, Black or American Indian heritage [2, 8]. A study based out of Colorado found an additional association with unmarried status [7] and another out of Washington State observed an association with low income [7]. Post-partum mental illness, in the form of post-partum depression or post-partum psychosis can be seen, with post-partum depression being much more common. Mothers with post-partum depression can have obsessional thoughts about them harming their child or checking impulses to ensure their baby is unharmed, however these mothers are less likely to harm their child. Mothers with post-partum psychosis who have delusions that their baby is evil are most likely significantly harm their child [9]. By contrast, data on victim characteristics (the infant) are relatively sparse [2, 10, 11]. It is also noteworthy that most of available data on infanticide are more than a decade old and trends in the components of infanticide (i.e., neonaticide and post-neonaticide) remain unexplored. Accordingly, the aim of this study is to examine previous and most recent trends in infanticide and its components covering the period 20032017. Further, we examined selected characteristics and predictors of infanticides, neonaticide and post-neonaticide.

Infanticide is a public health issue and several strategies of prevention have been proposed and implemented in society in an effort to address infanticide.

One of those solutions is Safe Haven Laws, in which a parent can legally surrender an infant who might otherwise be abandoned.

Texas was the first state to implement this law in 1999 and by 2008 Safe Haven Laws were in effect in all 50 states. Wilson et al, found that most homicides occurred among infants that, at the time of death, were too old for Safe Haven relinquishment. [8]. Another strategy has been earlier detection of post-partum depression and suicidal screening as $5 \%$ of mothers with young children also kill at least one of their kids. This can be done by asking depressed mothers what their plans would be for their children if they were to die, ask mothers about their thoughts and fears of harming their children. However, social stigmas and concerns that mothers will lose their children may prevent them from giving true responses [9]. Still other strategies include pregnancy prevention, so as to prevent unwanted pregnancies, and improved prenatal care when pregnancy does occur. However, the role of sex education in schools remains a controversial issue with conflicting study results regarding the impact of sex education on pregnancy prevention. Additionally, there are many barriers to getting adequate prenatal care, such as depression, denial of pregnancy, financial barriers, transportation barriers, child care barriers, etc. [10].

\section{Methods}

We utilized the Multiple Cause-of-Death Mortality Data for the years 2003-2017 from the National Vital Statistics System of the National Center for Health Statistics [13], which provides information on multiple cause of death for all deaths occurring within the United States. The information is abstracted from death certificates filed in vital statistics offices of each of the 50 states of the United States (US). Causes of death were coded according to the International Classification of Diseases, Tenth Revision (ICD-10) 1999 onwards. 
This study was approved as exempt through the Institutional Review Board of the Baylor College of Medicine.

For this study we restricted the data to deaths among infants ( $<1$ year of age) and further sub-classified them into neonates: $<28$ days old and post-neonates: 28 days to the day before their first birthday [14]. ICD-10 codes starting with X9 and Y0 were utilized to identify infanticides (homicide among infants), neonaticides (homicide among neonates) and post-neonaticides (homicide among post-neonates). Other covariates included in the study were: place of death which was sub-grouped into hospital (including inpatient, outpatient, emergency room (ER) and dead on arrival), decedent's home, and 'other'; sex which were available as male or female; race/ethnicity which was categorized as non-Hispanic (NH) White, NH-Black, Hispanic and other; resident status which was classified as residents (those for whom state and county of death and residence were the same), non-residents (those for whom state and county of death and residence were not the same, but both were in the US), foreign residents (state of death was one of the 50 States, but place of residence was outside of the US).

Using Joinpoint regression analysis technique [15], we calculated the trends in the rates of infanticide, neonaticide and post-neonaticide during the study period 2003-2017. Joinpoint regression is an innovative modeling technique which is utilized to examine the statistical trends in the rates of the outcome over a duration of time. This technique initially assumes zero joinpoints (change in trend) to fit the model. Subsequently joinpoints are added in singular increments till the best fitting, statistically significant model is achieved. Each change in trend in represented by annual percent change (APC) and the overall trend is depicted using the average annual percentage change (AAPC) and $95 \%$ confidence interval.

We explored the top 10 causes of death among those who suffered infanticide, neonaticide and post-neonaticide. All victims who had an ICD-10 diagnosis of "Homicide" were filtered. Of those children, their primary diagnoses were analyzed and listed by frequency. Next, we examined the socio-demographic characteristics among the victims of infanticide, neonaticide and post-neonaticide, and calculated the proportional incidences of each of the outcomes. Pearson's chi-squared test was utilized to examine the bivariate relationship between each of the socio-demographic variable and the three outcomes. Lastly, using logistic regression, we examined the risk factors associated with infanticide, neonaticide and post-neonaticide. All statistical analyses were performed using R (version $3 \cdot 6 \cdot 1$ ) and RStudio (Version 1 • 2 5001) and the Joinpoint Regression Program, version 4.7.0.0 (National Cancer Institute); we assumed a 5\% type I error rate for all hypothesis tests (two-sided).

\section{Results}

Within the 15 years of the study, a total of 385,386 deaths were recorded in the Center for Disease Control and Prevention (CDC) mortality data of birth cohorts which corresponds to a yearly average of about 25,692 infant deaths (Table 1). The total number of cases of infanticide during the study period was 4,545 which accounted for about $1.2 \%$ of all infant deaths. Of this number, 515 and 4,030 were cases of neonaticides and post-neonaticides accounting for $11.3 \%$ and $88.7 \%$, respectively. In Fig. 1, we present temporal trends for the proportional rates of infanticide, neonaticide and post-neonaticide over the period of the study. The data suggests that during the 15 -year period that was analyzed, infanticide has consistently accounted for about $1.2 \%$ of infant mortality each year. Both infanticide and post-neonaticide displayed a stable rate with no significant change in the average annual percent change (AAPC). By contrast, the trend trajectory for neonaticide portrayed a significant decline over time averaging a $4.2 \%$ drop on an annual basis as shown by the AAPC. 
Table 1

Socio-demographic characteristics of victims of infanticide, neonaticide and post-neonaticide

\begin{tabular}{|c|c|c|c|c|c|c|c|c|c|c|c|c|c|c|}
\hline & Total & & Infanti & ide & & & Neon & ticide & & & & st-Neonaticid & & \\
\hline & $\begin{array}{l}N= \\
385386\end{array}$ & Col $\%=100$ & $\begin{array}{l}N= \\
4545\end{array}$ & Col\%=100 & Row\% & & $\begin{array}{l}N= \\
515\end{array}$ & Col\%=100 & Row\% & & $\begin{array}{l}N= \\
4030\end{array}$ & Col\%=100 & Row\% & \\
\hline Place of death & & & & & & $\begin{array}{l}< \\
0.01\end{array}$ & & & & $\begin{array}{l}< \\
0.01\end{array}$ & & & & $\begin{array}{l}< \\
0.01\end{array}$ \\
\hline $\begin{array}{l}\text { Hospital } \\
\text { (inpatient, } \\
\text { outpatient, ER, } \\
\text { dead on } \\
\text { arrival) }\end{array}$ & 349753 & $90.8 \%$ & 3575 & $78.7 \%$ & $1.0 \%$ & & 222 & $43.1 \%$ & $0.1 \%$ & & 3353 & $83.2 \%$ & $1.0 \%$ & \\
\hline $\begin{array}{l}\text { Decendent's } \\
\text { home }\end{array}$ & 27161 & $7.0 \%$ & 641 & $14.1 \%$ & $2.4 \%$ & & 174 & $33.8 \%$ & $0.6 \%$ & & 467 & $11.6 \%$ & $1.7 \%$ & \\
\hline Other & 8472 & $2.2 \%$ & 329 & $7.2 \%$ & $3.9 \%$ & & 119 & $23.1 \%$ & $1.4 \%$ & & 210 & $5.2 \%$ & $2.5 \%$ & \\
\hline Sex & & & & & & 0.03 & & & & $\begin{array}{l}< \\
0.01\end{array}$ & & & & $\begin{array}{l}< \\
0.01\end{array}$ \\
\hline Female & 169875 & $44.1 \%$ & 1933 & $42.5 \%$ & $1.1 \%$ & & 249 & $48.3 \%$ & $0.1 \%$ & & 1684 & $41.8 \%$ & $1.0 \%$ & \\
\hline Male & 215511 & $55.9 \%$ & 2612 & $57.5 \%$ & $1.2 \%$ & & 266 & $51.7 \%$ & $0.1 \%$ & & 2346 & $58.2 \%$ & $1.1 \%$ & \\
\hline Race/ethnicity & & & & & & 0.02 & & & & $\begin{array}{l}< \\
0.01\end{array}$ & & & & $\begin{array}{l}< \\
0.01\end{array}$ \\
\hline NH-White & 172760 & $44.8 \%$ & 1956 & $43.0 \%$ & $1.1 \%$ & & 229 & $44.5 \%$ & $0.1 \%$ & & 1727 & $42.9 \%$ & $1.0 \%$ & \\
\hline NH-Black & 112992 & $29.3 \%$ & 1460 & $32.1 \%$ & $1.3 \%$ & & 135 & $26.2 \%$ & $0.1 \%$ & & 1325 & $32.9 \%$ & $1.2 \%$ & \\
\hline Hispanic & 78509 & $20.4 \%$ & 898 & $19.8 \%$ & $1.1 \%$ & & 102 & $19.8 \%$ & $0.1 \%$ & & 796 & $19.8 \%$ & $1.0 \%$ & \\
\hline Other & 17463 & $4.5 \%$ & 175 & $3.9 \%$ & $1.0 \%$ & & 24 & $4.7 \%$ & $0.1 \%$ & & 151 & $3.7 \%$ & $0.9 \%$ & \\
\hline Missing & 3662 & $1.0 \%$ & 56 & $1.2 \%$ & $1.5 \%$ & & 25 & $4.9 \%$ & $0.7 \%$ & & 31 & $0.8 \%$ & $0.8 \%$ & \\
\hline $\begin{array}{l}\text { Resident } \\
\text { status }\end{array}$ & & & & & & 0.09 & & & & $\begin{array}{l}< \\
0.01\end{array}$ & & & & 0.04 \\
\hline Residents & 243410 & $63.2 \%$ & 2934 & $64.6 \%$ & $1.2 \%$ & & 401 & $77.9 \%$ & $0.2 \%$ & & 2533 & $62.9 \%$ & $1.0 \%$ & \\
\hline Non-residents & 140933 & $36.6 \%$ & 1596 & $35.1 \%$ & $1.1 \%$ & & 102 & $19.8 \%$ & $0.1 \%$ & & 1494 & $37.1 \%$ & $1.1 \%$ & \\
\hline $\begin{array}{l}\text { Foreign } \\
\text { residents }\end{array}$ & 1043 & $0.3 \%$ & 15 & $0.3 \%$ & $1.4 \%$ & & 12 & $2.3 \%$ & $1.2 \%$ & & 3 & $0.1 \%$ & $0.3 \%$ & \\
\hline
\end{tabular}

Note: where the expected cell size was $<5$, Fisher's Exact test was used instead of the general Chi-square test.

$\mathrm{N}=$ number

Col\%= proportion of infanticide, neonaticide and post-neonaticide accounted for by that category. E.g. Among all deaths which were classified as infanticide, $78.7 \%$ occurred in the hospital.

Row $\%=$ proportion of deaths in that category classified as infanticide, neonaticide or post-neonaticide. E.g. Among all deaths in the hospital, $1.0 \%$ were classified as infanticide

Using ICD-10 code data, the top diagnoses assigned to each victim were assessed among each infanticide sub-type (Fig. 2). These were ICD-10 diagnostic codes assigned to each patient by the medical providers that cared for them. All patients had ICD-10 codes starting with X9 and Y0, as described in the methods section, to identify infanticides (homicide among infants), neonaticides (homicide among neonates) and post-neonaticides (homicide among postneonates). The diagnoses in Fig. 2 were the most common additional ICD-10 codes assigned to the patients. Some of the primary diagnoses seem to describe the method of homicide, others describe the assailant, and other describe the injury. The top reason for each of the infanticide sub-group was "Assault by unspecified means". Although the ICD-10 codes list a combination of method, perpetrator and injury, it is clear that within each sub-group, the majority of ICD10 codes are describing the method of the act. Other than "unspecified means", the most common methods were "assault by hanging, strangulation and suffocation", "asphyxiation", "assault by drowning and submersion", "assault by other and unspecified firearms and gun discharge". This information can be particularly useful when developing interventions aimed at reducing infanticide.

As seen in Table 1, among all infanticide deaths, the place of death was greatest in the hospital. This was also true for the proportion of neonaticide and postneonaticide. Overall, male infants accounted for a greater share of infanticide victims ( $57.5 \%$ versus $42.5 \%)$. This gender-based difference was also apparent for neonaticide and post-neonaticide. NH-Blacks accounted for about a third of cases of infanticide and post-neonaticide as well as one of every four cases of neonaticide. By contrast, Hispanics and NH-Whites had similar proportion of infanticide, neonaticide and post-neonaticide. Residents comprised a larger proportion of infanticide, neonaticide and post-neonaticide victims compared to non-residents and foreign residents.

In Table 2, we summarize the results of logistic regression models for the estimation of the association between the selected victim socio-demographic characteristics in Table 1. Regarding place of death, infanticide victims were more likely to die in the decedent's home compared to the hospital $(\mathrm{OR}=2.5,95 \%$ 
$\mathrm{Cl}=2.29-2.74)$, or more likely to die in a location designated as "other" compared to the hospital (OR $3.68,95 \% \mathrm{Cl}=2.54-6.07)$. A similar pattern was seen in neonaticide and post-neonaticide. Within neonaticide, victims were 9.64 times as likely to die in the decedent's home compared to the hospital (95\% $\mathrm{Cl}=7.77-$ 11.95). Compared to dying in the hospital, victims of post-neonaticide were 1.95 times as likely to die in the decedent's home $(95 \% \mathrm{Cl}=1.76-2.16, \mathrm{p}=<0.01)$. Compared to females, males were more likely to have a lethal outcome from infanticide (OR 1.07, p 0.02) and post-neonaticide ( $p<0.01)$. There was no statistical significance noted between genders in the neonaticide category. Regarding race/ethnicity, NH-Blacks were more likely to have a lethal outcome compared to $\mathrm{NH}-$ Whites by a factor of $1.23(\mathrm{p}<0.01)$ and Hispanics were more likely to have a lethal outcome compared to $\mathrm{NH}-\mathrm{Whites}$ with $\mathrm{OR}=1.10(95 \% \mathrm{Cl}$ : $1.04-1.18, p=0.03$ ). There was only a statistically significant difference noted among NH-Blacks compared to NH-Whites in the post-neonaticide category, with NH-Blacks being 1.25 times as likely to die (95\% Cl: 1.16-1.35, p<0.01). There was no statistical difference seen in Hispanics compared to NH-Whites in the post-neonaticide category and no statistical differences among any race/ethnicity group in the neonaticide category. Finally, compared to United States residents, non-residents were 1.12 times as likely to experience a lethal infanticide outcome ( $95 \% \mathrm{Cl}: 1.05-1.19, \mathrm{p}<0.01)$. This pattern was also seen in postneonaticide with non-residents being 1.16 times as likely to die compared to residents $(p<0.01)$. However, there was a protective effect noted in the neonaticide category with non-residents less likely to die compared to residents with $O R=0.76(p=0.02)$. This effect was opposite when foreign residents were compared to residents, foreign residents were more likely to have a lethal outcome with $O R=3.71(p<0.01)$ in the neonaticide category, while having a protective effect in the post-neonaticide category with the odds of death decreasing by a factor of $0.29(p=0.03)$.

Table 2

Risk factors associated with infanticide, neonaticide and post-neonaticide

\begin{tabular}{|c|c|c|c|c|c|c|}
\hline & \multicolumn{2}{|l|}{ Infanticide } & \multicolumn{2}{|l|}{ Neonaticide } & \multicolumn{2}{|l|}{ Post-neonaticide } \\
\hline & $\mathrm{OR}(95 \% \mathrm{Cl})$ & p-value & $\mathrm{OR}(95 \% \mathrm{Cl})$ & p-value & $\mathrm{OR}(95 \% \mathrm{Cl})$ & p-value \\
\hline \multicolumn{7}{|l|}{ Place of death } \\
\hline Hospital (inpatient, outpatient, ER, dead on arrival) & reference & & reference & & reference & \\
\hline Decedent's home & $2.5(2.29-2.74)$ & $<0.01$ & $9.64(7.77-11.95)$ & $<0.01$ & $1.95(1.76-2.16)$ & $<0.01$ \\
\hline Other & $3.68(2.54-6.07)$ & $<0.01$ & $5.93(2.16-9.91)$ & $<0.01$ & $2.43(1.37-4.46)$ & $<0.01$ \\
\hline \multicolumn{7}{|l|}{ Sex } \\
\hline Female & reference & & reference & & reference & \\
\hline Male & $1.07(1.01-1.14)$ & 0.02 & $0.85(0.71-1.01)$ & 0.06 & $1.1(1.04-1.18)$ & $<0.01$ \\
\hline \multicolumn{7}{|l|}{ Race/ethnicity } \\
\hline NH-White & reference & & reference & & reference & \\
\hline NH-Black & $1.23(1.15-1.32)$ & $<0.01$ & $1.07(0.86-1.33)$ & 0.53 & $1.25(1.16-1.35)$ & $<0.01$ \\
\hline Hispanic & $1.1(1.01-1.19)$ & 0.03 & $1.21(0.95-1.53)$ & 0.11 & $1.08(0.99-1.18)$ & 0.07 \\
\hline Other & $0.92(0.78-1.07)$ & 0.28 & $1.12(0.72-1.67)$ & 0.6 & $0.89(0.75-1.05)$ & 0.19 \\
\hline \multicolumn{7}{|l|}{ Resident status } \\
\hline Residents & reference & & reference & & reference & \\
\hline Non-residents & $1.12(1.05-1.19)$ & $<0.01$ & $0.76(0.6-0.96)$ & 0.02 & $1.16(1.08-1.24)$ & $<0.01$ \\
\hline Foreign residents & $1.17(0.66-1.88)$ & 0.56 & $3.71(1.79-7.05)$ & $<0.01$ & $0.29(0.07-0.75)$ & 0.03 \\
\hline \multicolumn{7}{|c|}{$\begin{array}{l}\text { Models show independent association between socio-demographic characteristics and each of the outcome variables - infanticide, neonaticide and post- } \\
\text { neonaticide }\end{array}$} \\
\hline
\end{tabular}

\section{Discussion}

Our analysis covering the two decades (2003-2017) showed that the yearly rate of infanticide as measured by the AAPC (average annual percent change) remained the same over the period of the study. However, neonaticide did portray a significant decline. Other findings included the preponderance of male infants among victims of infanticide and post-neonaticide compared to female infants; the higher likelihood for infanticide and post-neonaticide revealed among NH Blacks compared to NH-Whites; and the observation that foreign resident status had an almost four-fold increased likelihood for neonaticide while having a protective effect on post-neonaticide.

Some studies have reported similar results as ours in regards to gender and race/ethnicity disparities. Kunz et al. found that males were more likely to be victims of homicide between the ages of 1 week to 15 years [5]. Cummings, et al also found that male gender was predictive of intentional death in infants [11]. Kunz et al, also found that victims under 18 years of age were more likely to be African Americans [5]. Additionally, among children that were victims of homicide between 0-4 years of age, African Americans were more than four times as likely as to be victims compared to their White age peers [12]. A unique perspective in our study is the desegregation of infanticide into its two main phenotypes (namely, neonaticide and post-neonaticide) among Hispanic children as well, which showed no difference from those of $\mathrm{NH}$-Whites. Although when looking at infanticide as a whole, Hispanics were at slightly increased risk of infanticide as compared to $\mathrm{NH}-$ Whites. 
There are several proposed mechanisms at multiple levels that may result in the disparities seen in this study and it is imperative to understand the disparities that exist so as to appropriately address the issue by helping the groups of people who are most in need. Having a newborn and infant brings its own unique challenges and stresses. At the individual level, it is imperative to have good stress coping skills and demonstrate resilience. Inadequacy of stress coping skills could easily trigger loss of self-control leading to a violent act, which, depending on severity, could cause homicide. Certain coping mechanisms have been shown to be positively associated with age, which means that younger people can be less resilient in the face of stress if they don't possess positive coping mechanisms [16]. Additionally, immigrants may have a unique set of stresses, such as fear of deportation, and challenges that could render them less resilient in the face of stress, such as loss of social support [17]. Though this may change over time as immigrants develop new social networks, which may partially explain the protective effect of being a foreign resident in the post-neonaticide group [17]. Within the medical system, pediatricians, obstetricians and other essential team members in the clinical settings are a resource for those who are not coping well with stress, and could offer appropriate interventions. However, for clinicians to intervene, they have to be able to see their patients in clinic. Individuals of low SES, ethnic minorities and immigrants are those who have the most difficulty getting access to medical care. At a societal level, implicit bias may play a role. Not only could future infanticide prevention efforts be taken to address those who are at highest risk, young mothers, those with lack of prenatal care, etc. But the data from this study also suggests that preventive efforts should also specifically aid minority groups and immigrants.

Certain sources of bias that could impact our results are worth mention. There are many objective findings that differentiate accidental versus non-accidental injury, however there is some degree of subjectivity in determining the final diagnosis. The combination of subjectivity and also implicit bias may result in a disproportionate number of NH-Blacks being investigated for homicide. The manner by which deceased patients were assigned their race/ethnicity could induce information bias. The data was obtained from the National Vital Statistics System based on information abstracted from death certificate records. If race/ethnicity was not self-reported there could easily be some misclassification of race/ethnicity, particularly between Hispanic and Caucasian categorization. It is likely that such misclassification bias was random, which implies that the reported results in this study were likely underestimates.

There are a number of limitations in this study. It was quite challenging to determine the cause of death due to inconsistencies in phenotyping the diagnostic codes. For instance, while some diagnosis codes assigned described the assailant (e.g., parent) for cause of death, others specified the mechanism of the assault instead (e.g., firearm). This made it difficult to harmonize and rank the causes of death. Additionally, the diagnoses in Table 2 listed only the primary diagnosis, so if there were several diagnoses listed for a patient those were not included in our analysis. Despite these shortcomings, there are notable areas of strength. A strength in the study is that the database utilized for the analysis is comprehensive and encompasses every case of infanticide in the US. Furthermore, and to our knowledge, this is the largest nationwide study that examined racial/ethnic disparities by infanticide phenotypes in the US.

In summary, we found NH-Blacks were more likely to have a lethal outcome in the infanticide and post-neonaticide categories compared to NH-Whites. Foreign residents were more likely to be victims of neonaticide but less likely to be victims of post-neonaticide compared to residents. The proposed mechanisms for these disparities largely focus on the lack of resources being available to those who need them most. The major public health implication is that access to healthcare needs to be improved and community resources need to be made more available to address the proposed mechanisms that lead to infanticide.

\section{Declarations}

\section{Funding: N/A}

\section{Conflicts of interest/Competing interests: N/A}

Availability of data and material: Data will be made available upon request

Code availability: Codes will be made available upon request

Author Contributions - HMS conceived the idea and supervised the project, DNG drafted the manuscript, DD conducted all the analyses and drafted the manuscript.

Ethics approval: This study was approved as exempt through the Institutional Review Board of the Baylor College of Medicine.

\section{Consent to participate: N/A}

\section{Consent for publication: N/A}

\section{References}

1. Center for Disease Control and Prevention. Web-based Injury Statistics Query and Reporting System. WISQARS Injury Mortality Reports. Available at: https://www.cdc.gov/injury/wisqars/index.html

2. Overpeck MD, Brenner RA, Trumble AC, Trifiletti LB, Berendes HW. Risk factors for infant homicide in the United States. N Engl J Med.1998;339 (17):12111216

3. Fujiwara T, Barber C, Schaechter J, et al. Characteristics of Infant Homicides: Findings from a US Multisite Reporting System. Pediatrics. 2009;124(2):210217.

4. Herman-Giddens ME, Smith JB, Mittal M, Carlson M, Butts JD. Newborns killed or left to die by a parent: a population-based study. JAMA.2003;289 (11):1425- 1429

5. Kunz J, Bahr S. A profile of parental homicide against children. J Fam Violence 1996;11:347-362 
6. McCarroll JE, Fisher JE, Cozza SJ, et al. Characteristics, classification and prevention of child maltreatment fatalities. Military Medicine. 2017;182(1):e1551-e1557.

7. Siegel CD, Graves P, Maloney K, Norris JM, Calonge BN, Lezotte D. Mortality from intentional and unintentional injury among infants of young mothers in Colorado, 1986 to 1992. Arch Pediatr Adolesc Med 1996;150:1077-1083

8. Wilson RF, Klevens J, Williams D, et al. Infant homicides within the context of Safe Haven Laws- United States 2008-2017. Morbidity and Mortality Weekly Report. 2020:69(39):1385-1390.

9. Resnick PJ. Filicide in the United States. Indian Journal of Psychiatry. 2016;58(Suppl 2):S203-S209.

10. Schwartz LL, Isser N. (2007). Child Homicide: Preventive Measures. In Child Homicide. (p. 211-228). CRC Press.

11. Cummings P, Theis MK, Mueller BA, Rivara FP. Infant injury death in Washington State, 1981 through 1990. Arch Pediatr Adolesc Med 1994;148:10211026

12. Bennett Jr MD, Hall J, Frazier L, et al. Homicide of children aged 0-4 years, 2003-04: results from the National Violent Death Reporting System. Inj Prev. 2006;12:39-43.

13. The National Bureau of Economic Research. Mortality Data- Vital Statistics NCHS' Multiple Cause of Death Data, 1959-2017. Available at: https://data.nber.org/data/vital-statistics-mortality-data-multiple-cause-of-death.html

14. Center for Disease Control and Prevention. Morbidity and Mortality Weekly Report. Quick Stats: Leading causes of Neonatal and Postneonatal DeathsUnited States, 2002. Available at: https://www.cdc.gov/mmwr/preview/mmwrhtml/mm5438a8.htm

15. National Cancer Institute Division of Cancer Control and Population Sciences. Surveillance Research Program. Joinpoint Trend Analysis Software. Available at: https://surveillance.cancer.gov/joinpoint/

16. Leipold B, Munz M, et al. Coping and Resilience in the Transition to Adulthood. Emerging Adulthood. 2019;7(1):12-20.

17. Non AL, León-Pérez G, et al. Stress across generations: A qualitative study of stress, coping and caregiving among Mexican immigrant mothers. Ethnicity and Health. 2019;24(4):378-394.

\section{Figures}

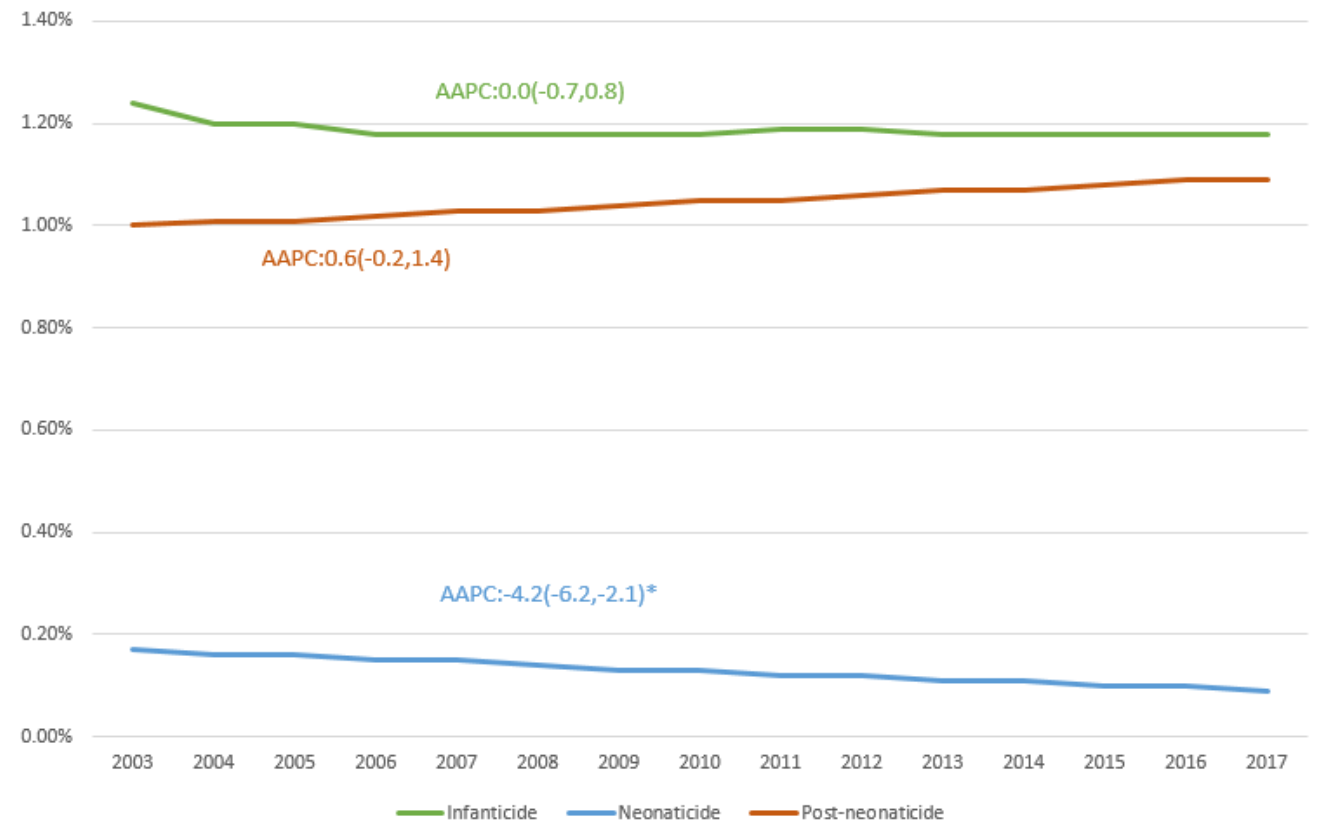

\section{Figure 1}

Trends in the proportional rates of infanticide, neonaticide and post-neonaticide in the US: 2003-2017 


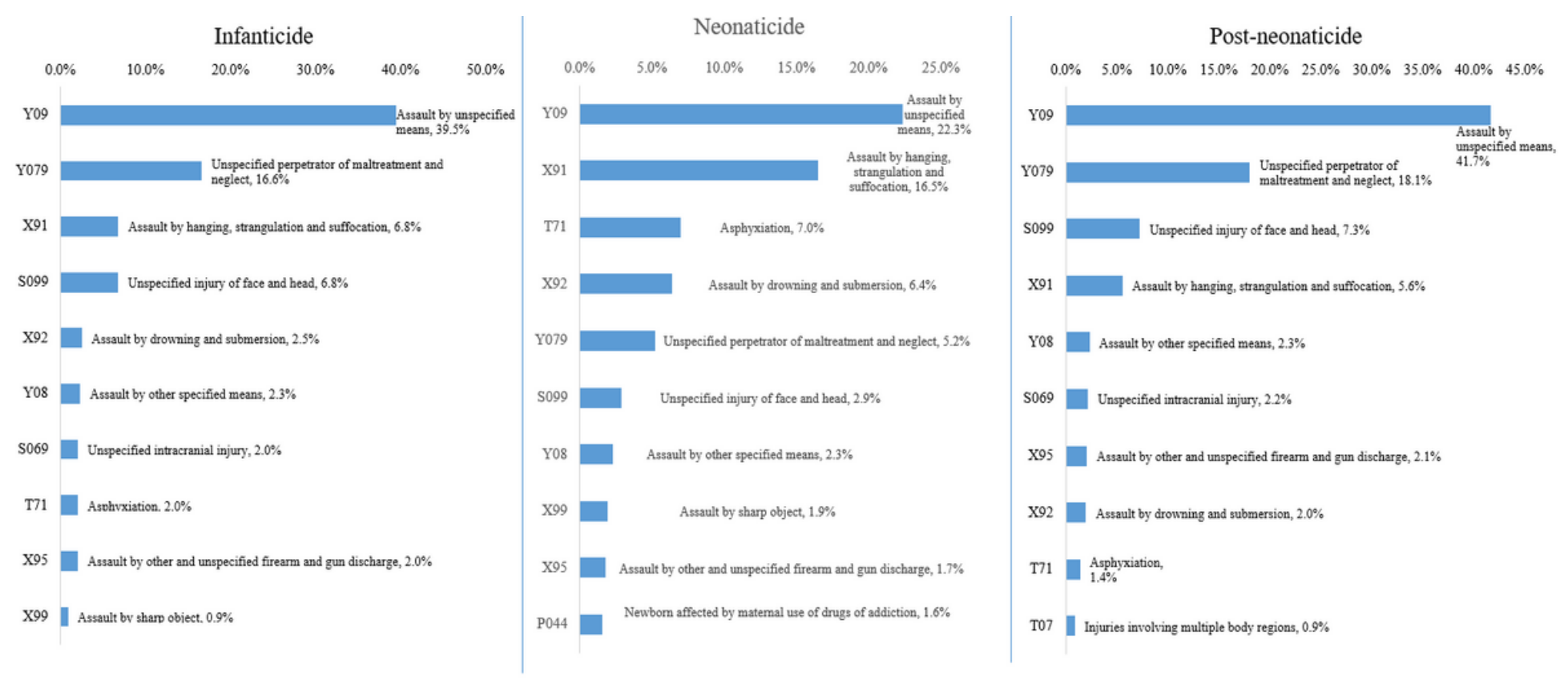

\section{Figure 2}

Top 10 causes of death among victims of infanticide, neonaticide and post-neonaticide 